\title{
EFEKTIVITAS JUS MENTIMUN TERHADAP PERUBAHAN TEKANAN DARAH PADA LANSIA PENDERITA HIPERTENSI DI LINGKUNGAN DASAN SARI WILAYAH KERJA PUSKESMAS PEJERUK
}

\author{
Eva Marvia ${ }^{1}$, Febriati Astuti ${ }^{2}$, Nurjanah Khaeriah ${ }^{3}$ \\ ${ }^{1,2,3)}$ Sekolah Tinggi Ilmu Kesehatan (STIKES) Mataram \\ Email:marvia_eva@yahoo.com
}

\begin{abstract}
ABSTRAK
Penyakit darah tinggi (hipertensi) merupakan penyakit yang digolongkan sebagai the silent killer (pembunuh diam-diam). Salah satu solusinya dengan pengobatan herbal yaitu dengan jus mentimun berfungsi untuk menurunkan tekanan darah tinggi. Tujuan penelitian ini untuk mengetahui efektivitas jus mentimun terhadap perubahan tekanan darah pada lansia penderita hipertensi di Lingkngan Dasan Sari.

Jenis penelitian yang digunakan adalah Quasi experimen dengan rancangan nonequivalent time sampel design. Polulasi dalam penelitian ini sebanyak 40 orang. Sampel sebanyak 40 responden dengan tehnik sampel total sampling di bagi menjadi dua yaitu kelompok perlakuan 20 dan kelompok kontrol 20. Pengumpulan data dengan menggunakan lembar observasi dan tindakan. Analisa data yang digunakan yaitu uji Mann-Whitney.

Hasil penelitian menunjukkan pada kelompok perlakuan sebelum melakukan pretest yang mengalami hipertensi ringan 15, sedang 4, berat 1 dan setelah posttest menjadi normal 20 responden (100\%). Sedangkan pada kelompok kontrol sebelum melakukan pretest yang mengalami hipertensi ringan 8 , sedang 7 , berat 5 dan setelah posttest menjadi normal 14 responden (70\%), ringan 6 responden $(30 \%)$. Berdasarkan hasil uji statistik menggunakan uji menn-whitney u program spss menunjukan bahwa nilai rata-rata pada kelompok perlakuan sebesar 17,50 sedangkan pada kelompok kontrol sebesar 23,50. Hasil ini menunjukan rata-rata pada kelompok perlakuan lebih rendah dibandingkan dengan kelompok kontrol. Didapatkan hasil dari uji mannwhitney u sebesar 0,009 dengan nilai signifikan 0.05 dimana $0,009<0,05$ sehingga $\mathrm{Ha}$ diterima.

Kesimpulan jus mentimun lebih efektif dibandingkan hanya di kontrol dengan minum obat anti hipertensi terhadap perubahan tekanan darah pada lansia penderita hipertensi di Lingkungan Dasan Sari wilayah kerja Puskesmas Pejeruk.
\end{abstract}

Kata kunci: Pemberian Jus Mentimun, Tekanan Darah, Hipertensi

\section{PENDAHULUAN}

Tua atau menua (Aging Process) adalah proses normal yang terjadi secara alamiah sepanjang masa kehidupan fisik dan tingkah laku sesuai tahap perkembangan kronologis tertentu. Proses menua dipengaruhi oleh fenomena yang kompleks dan multidimensial dimana tingkat kecepatannya berbeda pada setiap individu. Individu yang memasuki usia tua disebut lanjut usia (lansia). Menurut WHO, seseorang dikatakan lansia apabila sudah berumur 60 tahun atau lebih dan hal yang sama juga disebutkan dalam UU No. 13 tahun 1998, tentang kesejahteraan lanjut usia (Nugroho, 2014).

Jumlah lansia dan perkembangannya terus mengalami peningkatan. Menurut 
badan kesehatan dunia (WHO), proporsi penduduk lansia (>60 tahun) dunia akan berlipat ganda dari sekitar $11 \%$ pada tahun 2000 menjadi $22 \%$ pada tahun 205 dengan jumlah mutlak lansia diperkirakan meingkat 605 juta menjadi 2 miliyar. Indonesia pada tahun 2010 jumlah lansia tercatat 18,1 juta jiwa, tahun 2013 tercatat 26,4 juta jiwa, dan diperkirakan akan mencapai36 juta jiwa pada tahun 2020 (Depkes RI, 2014).

Berdasarkan data Badan Pusat Statistik, jumlah lansia di Provinsi NTB tahun 2011 adalah 155.550 jiwa, tahun 2012 sebanyak 159.400 jiwa, tahun 2013 sebanyak 164.000 jiwa, dan jumlahnya diperkirakan akan meningkat hingga hampir dua kali lipat pada tahun 2030, yaitu 288.900 jiwa. Usia yang semakin bertambah dapat menyebabkan kemunduran beberapa fungsi fisik maupun psikologi yang dialami lansia akibat proses menua (Aging Process) termasuk dapat menyebabkan masalah kesehatan pada lansia, salah satunya penyakit degeneratif yang sering dialami lansia yaitu hipertensi yang merupakan penyakit kronik akibat gangguan sistem sirkulasi darah yang kini menjadi masalah dalam kesehatan masyarakat (Dikes, 2013).

Menurut Badan Kesehatan Dunia (WHO) memperkirakan, prevalensi penderita hipertensi sekitarn 29\% penduduk terkena hipertensi, hipertensi masih merupakan tantangan besar di Indonesia. Penduduk berusia 18 tahun ke atas sudah mengalami hipertensi dimana hipertensi merupakan kondisi yang sering ditemukan pada pelayanan kesehatan primer. Hal itu merupakan masalah kesehatan dengan prevalensi yang tinggi, yaitu sebesar $25,8 \%$, sesuai dengan data. Sedangkan prevalensi penderita hipertensi di Nusa Tenggara Barat sekitar 32,4\% pada usia 60 tahun penduduk yang terkena hipertensi (Depkes RI, 2009).

Berdasarkan data yang didapatkan, jumlah penderita hipertensi di lingkungan dasan sari wilayah kerja puskesmas pejeruk berjumlah 40 orang lansia yang tersebar di 9 RT yang dimana hipertensi merupakan penyakit nomor 2 dari 10 penyakit terbanyak di puskesmas pejeruk.

Dalam mencagah dampak lebih buruk dari hipertensi maka harus dilakukan tindakan pencegahan dan pengobatan agar dapat mengendalikan tekanan darah. Beberapa cara yang dapat dilakukan untuk mengendalikan tekanan darah dapat dilakukan dengan terapi farmakologi yang biasanya diberikan dengan obat-obatan dan terapi non farmakologi yaitu terapi herbal, perubahan gaya hidup, kepatuhan dalam pengobatan, pengendalian stres, dan terapi relaksasi (Kowalski, 2010).

Salah satu cara pengobatan secara farmakologis dengan menggunakan obatobatan sintetis yang belakangan ini cenderung mengalami hambatan karena daya beli masyarakat yang semakin menurun, sehingga kita dapat memanfaatkan pengobatan secara non farmakologis dengan obat herbal. terapi herbal seperti Masasse punggung dan relaksasi napas dalam dapat menurunakan Hipertensi pada lansia (Sukardin, Sumartywati, Santosa, \& Rahman, 2018). Selain itu, bahan herbal berbahan baku mentimun yang bisa dijangkau dari segi manapun terutama materil dan mentimun banyak terdapat di masyarakat (Wibowo,2010).

Jus mentimun memiliki kandungan mineral yaitu postassium, magnesium, dan fosfor. Mentimun berfungsi untuk memelihara keseimbangan garam dan cairan serta mengontrol tekanan darah yang normal sedangkan asupan natrium, kalium, kalsium dan magnesium berhubungan dengan tingginya tekanan darah atau kejadian hipertensi, maka mentimun sangatlah bagus menjadi obat herbal untuk penyakit hipertensi (Nugraheni, 2016). Melihat kejadian hipertensi yang banyak terjadi di masyarakat. peneliti tertarik untuk 
meneliti "efektivitas jus mentimun terhadap perubahan tekanan darah pada lansia penderita hipertensi di Lingkungan Dasan Sari Wilayah Kerja Puskesmas Pejeruk".

\section{METODE PENELITIAN}

\section{A. Desain Penelitian}

Desain penelitian yang digunakan dalam penelitianini menggunakan quasi experimen dengan rancangan non- equivalent time sampel design. Dimana pada penelitian ini sampel kelompok intervensi diberikan perlakuan dan sampel kontrol tidak diberikan perlakuan, diobservasi lebih dahulu sebelum diberikan perlakuan sampel tersebut diobservasi kembali (Hidayat, 2007).

\section{B. Populasi, Sampel Dan Tehnik} Sampling

1. Populasi Penelitian

Pada penelitian ini yang menjadi populasi adalah sejumlah 40 orang pederita hipertensi.

2. Sampel adalah sebagian atau wakil dari populasi yang diteliti (Arikunto, 2010). Sampel dalam penelitian ini berjumlah 40 responden.

3. Teknik sampling merupakan caracara yang ditempuh dalam mengambil sampel, agar memperoleh sampel yang benarbenar sesuai dengan keseluruhan subjek penelitian. Teknik pengambilan sampel dalam penelitian ini menggunakan total sampling yaitu suatu teknik pengambilan sampel dengan cara semua populasi dijadikan sampel (Nursalam, 2011).

\section{Tehnik Penelitian}

Penelitian ini dilakukan selama 2 minggu, $\mathrm{d}$ ari hari pertama sampai hari ke empat belas. peneliti melakukan penelitian pada 40 responden dimana 20 pada kelompok perlakuan diberikan jus mentimun dan 20 pada kelompok kontrol tidak diberikan perlakuan hanya melakukan pengamatan pada tekanan darahnya. Sebelum melakasanakan tindakan, peneliti terlebih dahulu menjelaskan tujuan penelitian dan responden diminta menandatangani surat permohonan bersedian menjadi responden.

Peneliti langsung melakukan pre-test dengan mengukur tekanan darah terlebih dahulu sebelum diberikan perlakuan. Pada kelompok perlakuan peneliti memberikan jus mentimun selama 20-30 menit sebelum sarapan dan sebelum makan malam. Peneliti memberikan 2 kali perlakuan dalam 1 hari. Setelah diberikan perlakuan peneliti langsung melakukan post-test dimana reponden diukur kembali tekanan darahnya setelah diberikan jus mentimun, apakah responden mengalami hipertensi ringan, sedang, atau berat pada kelompok perlakuan sedangkan pada kelompok kontrol peneliti mengukur tekanan darah lalu di observasi kembali. Data hipertensi responden kelompok perlakuan dan kelompok kontrol sebelum dan sesudah pemberian diolah mengunakan uji statistik (mannWhitney-test) untuk mengetahui apakah jus mentimun efektif terhadap perubahan tekanan darah pada lansia penderita hipertensi.

D. Identifikasi Variabel Penelitian

Adapun Variabel independen dalam penelitian ini adalah Efektivitas Jus Mentimun, sedangkan Variabel dependen dalam penelitian ini adalah Perubahan Tekanan Darah. 


\section{HASIL DAN PEMBAHASAN}

\section{Hasil Penelitian}

A. Mengidentifikasi tekanan darah sebelum pemberian jus mentimun

Tabel 1. Distribusi Tekanan Darah Responden Sebelum Pemberian Jus Mentimun Pada Kelompok Perlakuan

\begin{tabular}{|c|l|c|c|}
\hline No & \multicolumn{1}{|c|}{ Kategori } & $\mathrm{F}$ & Presentase \\
\hline 1 & $\begin{array}{l}\text { Tekanan darah } \\
\text { (normal) }\end{array}$ & 0 & 0 \\
\hline 2 & $\begin{array}{l}\text { Hipertensi } \\
\text { Ringan }\end{array}$ & 15 & $75 \%$ \\
\hline 3 & $\begin{array}{l}\text { Hipertensi } \\
\text { Sedang }\end{array}$ & 4 & $20 \%$ \\
\hline 4 & Hipertensi Berat & 1 & $5 \%$ \\
\hline \multicolumn{2}{|c|}{ Total } & 20 & $100 \%$ \\
\hline
\end{tabular}

Berdasarkan hasil penelitian menunjukan bahwa tekanan darah responden sebelum pemberian jus mentimun pada kelompok pelakuan sebagian besar kategori hipertensi ringan sebanyak 15 responden $(75 \%)$, hipertensi sedang sebanyak 4 responden (20\%) dan hipertensi berat sebanyak 1 responden $(5 \%)$.

B. Distribusi Tekanan Darah Responden Pada Kelompok kontrol

\section{Tabel 2. Distribusi Tekanan Darah Responden Pada Kelompok kontrol}

\begin{tabular}{|c|c|c|c|}
\hline No & Kategori & $\mathrm{F}$ & Presentase \\
\hline 1 & $\begin{array}{c}\text { Tekanan darah ( } \\
\text { normal) }\end{array}$ & 0 & 0 \\
\hline 2 & $\begin{array}{l}\text { Hipertensi } \\
\text { Ringan }\end{array}$ & 8 & $40 \%$ \\
\hline 3 & $\begin{array}{l}\text { Hipertensi } \\
\text { Sedang }\end{array}$ & 7 & $35 \%$ \\
\hline 4 & Hipertensi Berat & 5 & $25 \%$ \\
\hline \multicolumn{2}{|r|}{ Total } & 20 & $100 \%$ \\
\hline
\end{tabular}

menunjukan bahwa tekanan darah responden pada kelompok kontrol sebagian besar pada kategori hipertensi ringan sebanyak 8 responden (40\%), hipertensi sedang sebanyak 7 responden (35\%) dan hipertensi berat sebanyak 5 responden $(25 \%)$.

C. Mengidentifikasi tekanan darah setelah pemberian jus mentimun Tabel 3. Distribusi Tekanan Darah Responden Setelah Pemberian Jus Mentimun Pada Kelompok Perlakuan

\begin{tabular}{|c|l|c|c|}
\hline No & \multicolumn{1}{|c|}{ Kategori } & F & Presentase \\
\hline 1 & $\begin{array}{l}\text { Tekanan darah } \\
\text { (normal) }\end{array}$ & 20 & $100 \%$ \\
\hline 2 & $\begin{array}{l}\text { Hipertensi } \\
\text { Ringan }\end{array}$ & 0 & 0 \\
\hline 3 & $\begin{array}{l}\text { Hipertensi } \\
\text { Sedang }\end{array}$ & 0 & 0 \\
\hline 4 & Hipertensi Berat & 0 & 0 \\
\hline \multicolumn{2}{|l|}{ Total } & 20 & $100 \%$ \\
\hline
\end{tabular}

Berdasarkan tabel di atas menunjukan bahwa tekanan darah responden sesudah pemberian jus mentimun pada kelompok pelakuan, semua responden pada kategori tekanan darah normal sebanyak 20 responden (100\%).

D. Distribusi Tekanan Darah Responden Pada Kelompok Kontrol

Tabel 4. Distribusi Tekanan Darah Responden Pada Kelompok Kontrol

\begin{tabular}{|c|c|c|c|}
\hline No & Kategori & $\mathrm{F}$ & Presentase \\
\hline 1 & $\begin{array}{l}\text { Tekanan darah } \\
\text { (normal) }\end{array}$ & 14 & $70 \%$ \\
\hline 2 & $\begin{array}{l}\text { Hipertensi } \\
\text { Ringan }\end{array}$ & 6 & $30 \%$ \\
\hline 3 & $\begin{array}{l}\text { Hipertensi } \\
\text { Sedang }\end{array}$ & 0 & 0 \\
\hline 4 & Hipertensi Berat & 0 & 0 \\
\hline \multicolumn{2}{|r|}{ Total } & 20 & $100 \%$ \\
\hline
\end{tabular}

Berdasarkan menunjukan bahwa tekanan darah
responden pada kelompok kontrol sebagian besar tekanan darah normal sebanyak 14 responden (70\%) sedangkan hipertensi ringan sebanyak 6 responden $(30 \%)$.

E. Analisa efektivitas jus mentimun terhadap perubahan tekanan darah pada lansia penderita hipertensi di wilayah kerja puskesmas pejeruk 
Berdasarkan hasil uji statistik menggunakan uji menn-whitney test program spss 16 menunjukan bahwa nilai rata-rata pada kelompok perlakuan sebesar 17,50 sedangkan pada kelompok kontrol menunjukan bahwa nilai rata-rata pada kelompok kontrol sebesar 23,50. Hasil ini menunjukan rata- rata pada kelompok perlakuan lebih rendah dibandingkan dengan kelompok kontrol. Didapatkan hasil dari uji mann-whitney sebesar 0,009 dengan nilai signifikan 0.05 dimana 0,009 $<0,05$ sehingga Ha diterima dan $\mathrm{H} 0$ ditolak. Hal ini menunjukkan bahwa pada kelompok perlakuan yang di berikan jus mentimun lebih efektif dibandingkan kelompok kontrol.

\section{Pembahasan}

Berdasarkan hasil penelitian didapatkan bahwa Sebelum dilakukan pemberian jus mentimun, tekanan darah responden pada kelompok perlakuan bervariasi, ada yang hipertensi ringan sebanyak 15 responden (75\%), hipertensi sedang sebanyak 4 responden (20\%) dan hipertensi berat sebanyak 1 responden $(5 \%)$ sedangkan tekanan darah responden pada kelompok kontrol ada yang hipertensi ringan sebanyak 8 responden $(40 \%)$, hipertensi sedang sebanyak 7 responden $(35 \%)$ dan hipertensi berat sebanyak 5 responden (25\%). Hal ini menunjukkan perbedaan paparan faktor yang dialamai setiap responden. Secara anatomis keelastisan pembuluh darah menjadi berkurang, akibatnya efektifitas tubuh juga akan berkurang. Usia yang semakin bertambah dapat menyebabkan kemunduran beberapa fungsi fisik maupun psikologi yang dialami lansia akibat proses menua (Aging Process) termasuk dapat menyebabkan masalah kesehatan pada lansia, salah satunya penyakit degeneratif yang sering dialami lansia yaitu hipertensi yang merupakan penyakit kronik akibat gangguan sistem sirkulasi darah yang kini menjadi masalah dalam kesehatan masyarakat.

Berdasarkan hasil penelitian yang di peroleh, bahwa, setelah dilakukan pemberian jus mentimun didapatkan tekanan darah, pada kelompok perlakuan didapatkan hasil pengukuran tekanan darah normal sebanyak 20 responden $(100 \%)$. Sedangkan pada kelompok kontrol didapatkan hasil pengukuran tekanan darah yaitu dengan kategori tekanan darah normal sebanyak 14 responden (70\%) dan hipertensi ringan sebanyak 6 responden (30\%). Dari hasil penelitian dapat dilihat bahwa pemberian jus mentimun sangat efektif untuk menurunkan tekanan darah di bandingakan dengan kelompok kontrol yang tidak diberikan perlakuan atau jus mentimun.

Jus mentimun mempunyai manfaat yang lain bagi kesehatan yaitu untuk memelihara keseimbangan garam dan cairan serta mengontrol tekanan darah, membantu menurunkan tekanan darah. Selain itu manfaat dari jus mentimun adalah sebagai diuresis terbaik, yakni sebagai pelancar air seni (Nugraheni, 2016).

Kandungan mentimun yang berperan dalam meregulasi tekanan darah adalah potasium/kalium yang tinggi akan meningkatkan konsentrasi didalam cairan intraseluler, sehingga cenderung menarik cairan dari bagian ekstraseluler dan menurunkan tekanan darah karena efek vasodilatasi pembuluh darah, kalium merupakan ion utama didalam cairan intrasel yang bekerja berkebalikan dari natrium/garam (Astawan, 2008). 


\section{Kesimpulan}

1. Sebelum dilakukan pemberian jus mentimun pada kelompok pelakuan tekanan darah pada responden yaitu: hipertensi ringan sebanyak 15 responden $(75 \%)$, hipertensi sedang sebanyak 4 responden (20\%) dan hipertensi berat sebanyak 1 responden (5\%) sedangkan pada kelompok kontrol tekanan darah responden yaitu: hipertensi ringan sebanyak 8 responden (40\%), hipertensi sedang sebanyak 7 responden $(35 \%)$ dan hipertensi berat sebanyak 5 responden (25\%).

2. Setelah dilakukan pemberian jus mentimun pada kelompok pelakuan, tekanan darah pada responden yaitu : tekanan darah normal sebanyak 20 responden, (100\%) sedangkan pada kelompok kontrol tekanan darah responden yaitu: tekanan darah nornal sebanyak 14 responden (70\%), hipertensi ringan sebanyak 6 responden $(30 \%)$.

3. Didapatkan hasil dari uji mann-whitney sebesar 0,009 dengan nilai signifikan 0.05 dimana $0,009<0,05$ sehingga Ha diterima dan $\mathrm{H} 0$ ditolak.

\section{DAFTAR PUSTAKA}

Arikunto, Suharsimi 2010. Prosedur penelitian suatu pendekatan praktik. Jakarta: PT. Rineka Cipta.

Astawan M dan Andre LK. 2008. Khasiat Warna Warni Makanan. Jakarta. Gramedia Pustaka Utama .

Depkes RI. 2009. Indonesia Semakin Sehat. Laporan

Depkes RI. 2014. Pelayanan Dan Peningkatan Kesehatan Usia Lanjut. Jakarta.

DinKes Kota Mataram. 2013. Profil Dinas Kesehatan Kota Mataram.

Hidayat, A.A.A. 2007. Metode Penelitian Keperawatan dan Teknik Analisis Data. Jakarta. Salemba Medika.

Kowalski, Robert. 2010. Terapi Hipertensi: Program 8 minggu Menurunkan Tekanan Darah Tinggi. Alih Bahasa: Rani Ekawati. Bandung: Qanita Mizan Pustaka.

Nugraheni. 2016. Raja Obat Alami: Mentimun A-Z Seri Apotik Dapur, Edisi 1. Yogyakarta.

Nugroho. 2014. Keperawatan Gerontik. EGC. Jakarta.

Nursalam. 2011. Manajemen Keperawatan.edisi 3. Jakarta: Salemba Medika

Nursalam. 2016. Konsep dan Penerapan Metodologi Penelitian Ilmu Keperawatan. Pedoman Skripsi, Tesis, dan Instrumen Penelitian Keperawatan. Salemba Medika.

Sukardin, Sumartywati, N.M., Santosa, I. M.E., \& Rahman, F. (2018). Pengaruh Pemberian Masase Punggung dan Relaksasi Nafas Dalam terhadap Penurunan Tekanan Darah pada Lansia di BSLU Mataram. PrimA: Jurnal Ilmiah Ilmu Kesehatan STIKES Mataram, 4(2), 57-65.

Wibowo M.A. 2010. Pengaruh Pemberian Jus Mentimun Terhadap Penurunan Tekanan Darah Sistolik Dan Diastolik Penderita Hipertensi Esensial Pada Lansia Di PSTW Budi Luhur. Skripsi Yogyakarta. 